\title{
Emergence of Leaf Spot Disease on Leafy Vegetable and Ornamental Crops Caused by Paramyrothecium and Albifimbria Species
}

\author{
Slavica Matić, ${ }^{1, \dagger}$ Giovanna Gilardi, ${ }^{1}$ Maria Lodovica Gullino, ${ }^{1,2}$ and Angelo Garibaldi ${ }^{1}$ \\ ${ }^{1}$ Centre of Competence for the Innovation in the Agro-environmental Sector (AGROINNOVA), Università di Torino, 10095 Grugliasco, Torino, \\ Italy \\ ${ }^{2}$ Department of Agricultural, Forestry and Food Sciences, Università di Torino, 10095 Grugliasco, Torino, Italy \\ Accepted for publication 16 January 2019.
}

\begin{abstract}
The genera Paramyrothecium and Albifimbria have been established from the former genus Myrothecium and they generally comprise common soilinhabiting and saprophytic fungi. Within these genera, only two fungi have been recognized as phytopathogenic thus far: $P$. roridum and $A$. verrucaria, both of which cause necrotic leaf spots and plant collapse. Severe leaf necrosis and plant decay have been observed in Northern and Southern Italy on leafy vegetable crops. Thirty-six strains of Paramyrothecium- and Albifimbria-like fungi were isolated from affected plants belonging to eight different species. Based on morphological characteristics, 19 strains were assigned to $A$. verrucaria, whereas the remaining strains, which mostly resembled Paramyrothecium-like fungi, could not be identified precisely. Molecular characterization of six loci (internal transcribed spacer [ITS], $\beta$-tubulin [tub2], calmodulin [ $\mathrm{cmdA}$ ], translation elongation

factor 1-alpha [tef1], large subunit ribosomal RNA [LSU], and mitochondrial ATP 6synthase 6 [ATP6]) of the 36 new isolates and three previously ITS-characterized isolates assigned all strains to four species: $A$. verrucaria, $P$. roridum, $P$. foliicola, and $P$. nigrum. Single and concatenated phylogenetic analyses were conducted, and they clearly distinguished the isolated fungi into four different groups. A. verrucaria, $P$. roridum, $P$. foliicola, and $P$. nigrum were able to induce leaf necrosis singly, and they were confirmed to be the causal agents of the leaf spot disease through pathogenicity assays. The involvement of fungi previously considered saprophytic (i.e., $P$. foliicola and $P$. nigrum) in the development of plant disease for the first time deserves particular attention because of the possibility of their transmission by seeds and the limited knowledge of their management with chemicals.
\end{abstract}

Species of the genera Paramyrothecium and Albifimbria (formerly in the genus Myrothecium) (Lombard et al. 2016) are common soil inhabitants and saprophytes of decaying plant material worldwide (Domsch et al. 2007). They are efficient cellulose decomposers and have been used as biopesticides for the control of weeds, nematodes, and insects (Abbas et al. 2001; Perry et al. 2000; Zhao et al. 2011). The former genus, Myrothecium, was subjected to a profound revision (Lombard et al. 2016), which resulted in the recognition of 13 new genera on the basis of the polyphyletic origin of its species, and more than 15 species have been reported within two renamed genera, Paramyrothecium and Albifimbria. Despite the large number of species, only two of them (P. roridum and $A$. verrucaria) include important plant pathogens (Chen et al. 2016, 2018; Garibaldi et al. 2016a; Tulloch 1972). Both species cause similar types of leaf spot disease in various cultivated vegetable and ornamental hosts. $P$. roridum affects various economic crops, including tomato, cucurbits, pepper, lamb's lettuce, cotton, soybean, Petunia spp., Rieger begonia, Anthurium andraeanum, and others (Ben et al. 2015a, 2015b, 2017; Farr and Rossman 2018; Fish et al. 2012; Garibaldi et al. 2016a; Quezado Duval et al. 2010). A. verrucaria also infects important crops such as beet, spinach, sunflower, peanut, cotton, potato, wild rocket, and ornamental plants (Abbas et al. 2001; Farr and Rossman 2018; Garibaldi et al. 2016b, 2016c). $P$. roridum was previously reported in Italy on tomato and gardenia

\section{${ }^{\dagger}$ Corresponding author: S. Matić; slavica.matic@unito.it}

Funding: This research was supported by funding from the European Union Horizon 2020 Research and Innovation Program under grant agreement number 634179 ("Effective Management of Pests and Harmful Alien Species-Integrated Solutions" [EMPHASIS])

*The $\boldsymbol{e}$-Xtra logo stands for "electronic extra" and indicates that two supplementary figures and three supplementary tables are published online.

The author(s) declare no conflict of interest.

(c) 2019 The American Phytopathological Society
(Cappelli 1996; Ciccarone 1953), whereas A. verrucaria was reported on rice (De Carolis 1972). However, the appearance of $P$. roridum and $A$. verrucaria on new hosts has increased, and these two species were observed for the first time in Italy in 2015 on leafy vegetable crops such as spinach, lamb's lettuce, and wild rocket (Gilardi et al. 2018).

Both $P$. roridum and $A$. verrucaria have been associated with the production of macrocyclic trichothecene (TRI) mycotoxins, such as verrucarin, roridin, epiroridin, mytoxin $\mathrm{B}$, and epiroridin acid (Bosio et al. 2017; Liu et al. 2016; Siciliano et al. 2017; Weaver et al. 2009). These TRI compounds are phytotoxic and have cytotoxic mechanisms in humans (Chen et al. 2016). Their mode of action has allowed them to be used as bioherbicides for various weeds (Anderson and Hallett 2004; Lee et al. 2008; Weaver et al. 2016).

Species of the former genus Myrothecium were previously identified through the morphological characteristics of their asexual structures, particularly those of conidiophores and conidia. The difficulties involved in the clear differentiation between several Paramyrothecium spp., owing to their limited distinct morphological characteristics, have encouraged the development of molecular detection techniques to support their morphological characterization. These molecular techniques are based on the amplification and sequencing of the commonly used internal transcribed spacer (ITS) fungal barcoding marker and/or other genes (Chen et al. 2016; Krisai-Greilhuber et al. 2017; Lombard et al. 2016; Ruma et al. 2015; Trapp et al. 1998).

The objective of this study was to characterize the causal agents of leaf spot disease and collapse of eight different plant hosts on a molecular basis. Isolated fungal species were characterized by means of multilocus phylogenetic analyses. Pathogenicity tests and host range studies were carried out as well to evaluate disease severity and identify possible new hosts.

\section{MATERIALS AND METHODS}

Fungal isolates and morphological identification. Various leafy vegetable and ornamental crops (15 to 30 days after emergence) with necrotic leaf spot symptoms, which were grown 
in plastic houses and gardens, were collected between 2015 and 2018 in different areas in Northern and Southern Italy. Thirty-six fungal isolates obtained from leaf-spot samples of eight plant species (lettuce, lamb's lettuce, cultivated rocket, wild rocket, spinach, basil, orange coneflower, and Echinacea sp.) were used in this study (Table 1). Additionally, three fungal strains (PnITS4, AvITS6, and AvITS7), which were previously characterized on a morphological and molecular basis (ITS region) from lamb's lettuce, wild rocket, and spinach plants with leaf spot symptoms (Garibaldi et al. 2016a, 2016b, 2016c), were also used in this study (Table 1).

Isolations were performed from symptomatic leaves by dipping small sections of the leaves into $1 \%$ sodium hypochlorite, then rinsing them in sterile water and plating them in triplicate on $15 \mathrm{ml}$ of potato dextrose agar (PDA; Merck, Darmstadt, Germany) amended with $25 \mathrm{mg}$ per liter of streptomycin (Applichem, Darmstadt, Germany). Monoconidial cultures were prepared from each isolate and stored in $30 \%$ glycerol solution at $-80^{\circ} \mathrm{C}$. The 36 new isolates were identified morphologically as described by Lombard et al. (2016), based on microscopic observations of the conidial shape and size, and through an examination of the colonies.

DNA extraction and sequence amplification. An E.Z.N.A. Fungal DNA Mini Kit (Omega Bio-Tek, Darmstadt, Germany) was used to extract the total DNA of 39 isolates from $100 \mathrm{mg}$ of mycelium grown on PDA dishes according to the manufacturer's instructions. Molecular identification was performed through amplification of the ITS (White et al. 1990), $\beta$-tubulin (tub2; Glass and Donaldson 1995), calmodulin (cmdA; Carbone and Kohn 1999; Groenewald et al. 2013), translation elongation factor 1-alpha (tefl; Carbone and Kohn 1999; O'Donnell et al. 1998), mitochondrial ATP synthase 6 (ATP6; Castlebury et al. 2004), and large subunit ribosomal RNA (LSU; Rehner and Samuels 1995; Vilgalys and Hester 1990). The primers used for the molecular identification are listed in Supplementary Table S1. The polymerase chain reaction (PCR) products were purified using a QIAquick PCR purification kit (Qiagen, Hilden, Germany) according to the manufacturer's instructions and sequenced in both directions (BMR Genomics Centre, Padua, Italy). All sequences were deposited in GenBank under the following accession numbers: ITS (MH707376 to MH707410, MH324475), tub2 (MH824702 to MH824740), cmdA (MH807735 to MH807773), tef1 (MH939202 to MH939240), ATP6 (MH898688 to MH898726), and LSU (MH807502 to MH807540), with the exception of isolates PnITS4, AvITS6, and AvITS7, which were sequenced previously at the ITS region (Garibaldi et al. 2016a, b, c). The accession numbers of the reference isolates (Lombard et al. 2016) are also included in Supplementary Table S2.

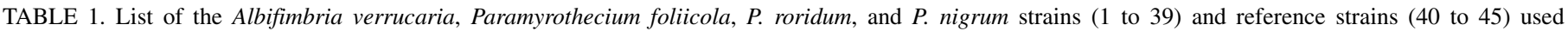
in this study

\begin{tabular}{|c|c|c|c|c|c|c|}
\hline No. & Isolate & Host & Origin of isolation & Year of isolation & Location & Species \\
\hline 1 & $2-1$ & Lettuce & Leaf & 2015 & Northern Italy & A. verrucaria \\
\hline 2 & $2-2$ & Lettuce & Leaf & 2015 & Northern Italy & A. verrucaria \\
\hline 3 & PnITS4 & Lamb's lettuce & Leaf & 2015 & Northern Italy & P. nigrum \\
\hline 4 & $4-1$ & Lamb's lettuce & Leaf & 2015 & Northern Italy & P. nigrum \\
\hline 5 & $4-2$ & Lamb's lettuce & Leaf & 2015 & Northern Italy & A. verrucaria \\
\hline 6 & $4-3$ & Lamb's lettuce & Leaf & 2015 & Northern Italy & P. nigrum \\
\hline 7 & $5-1$ & Lettuce & Leaf & 2015 & Northern Italy & P. nigrum \\
\hline 8 & $5-2$ & Lettuce & Leaf & 2015 & Northern Italy & P. nigrum \\
\hline 9 & 5-3 & Lettuce & Leaf & 2015 & Northern Italy & P. nigrum \\
\hline 10 & AvITS6 & Spinach & Leaf & 2015 & Northern Italy & A. verrucaria \\
\hline 11 & 6-1 & Spinach & Leaf & 2015 & Northern Italy & A. verrucaria \\
\hline 12 & $6-2$ & Spinach & Leaf & 2015 & Northern Italy & A. verrucaria \\
\hline 13 & $6-3$ & Spinach & Leaf & 2016 & Northern Italy & A. verrucaria \\
\hline 14 & $6-4$ & Spinach & Leaf & 2015 & Northern Italy & A. verrucaria \\
\hline 15 & $6-5$ & Spinach & Leaf & 2015 & Northern Italy & A. verrucaria \\
\hline 16 & AvITS7 & Wild rocket & Stem & 2015 & Southern Italy & A. verrucaria \\
\hline 17 & 7-1 & Wild rocket & Leaf & 2015 & Southern Italy & A. verrucaria \\
\hline 18 & 8 & Lamb's lettuce & Stem & 2016 & Northern Italy & A. verrucaria \\
\hline 19 & $8-1$ & Lamb's lettuce & Leaf & 2016 & Northern Italy & A. verrucaria \\
\hline 20 & $8-2$ & Lamb's lettuce & Leaf & 2016 & Northern Italy & A. verrucaria \\
\hline 21 & $8-3$ & Lamb's lettuce & Leaf & 2016 & Northern Italy & A. verrucaria \\
\hline 22 & $9-1$ & Wild rocket & Leaf & 2016 & Southern Italy & P. foliicola \\
\hline 23 & $10-1$ & Lettuce & Leaf & 2016 & Northern Italy & A. verrucaria \\
\hline 24 & $11-1$ & Lettuce & Leaf & 2017 & Southern Italy & A. verrucaria \\
\hline 25 & $12-1$ & Basil & Seed & 2017 & Not available & P. nigrum \\
\hline 26 & $13-1$ & Basil & Leaf & 2017 & Northern Italy & P. nigrum \\
\hline 27 & $14-1$ & Cultivated rocket & Leaf & 2015 & Northern Italy & P. nigrum \\
\hline 28 & $14-2$ & Cultivated rocket & Leaf & 2015 & Northern Italy & P. nigrum \\
\hline 29 & Rful & Orange coneflower & Leaf & 2017 & Northern Italy & P. nigrum \\
\hline 30 & Bas5_18 & Basil & Seed & 2018 & Not available & A. verrucaria \\
\hline 31 & Bas4_1b & Basil & Seed & 2018 & Not available & P. foliicola \\
\hline 32 & Bas3_m3 & Basil & Seed & 2018 & Not available & A. verrucaria \\
\hline 33 & Bas3_1a & Basil & Seed & 2018 & Not available & A. verrucaria \\
\hline 34 & Bas4_m1 & Basil & Seed & 2018 & Not available & A. verrucaria \\
\hline 35 & Bas4_m2 & Basil & Seed & 2018 & Not available & P. foliicola \\
\hline 36 & AGR1r1 & Orange coneflower & Leaf & 2017 & Northern Italy & $P$. roridum \\
\hline 37 & AGR1r2 & Orange coneflower & Leaf & 2017 & Northern Italy & P. nigrum \\
\hline 38 & AGR2r2 & Orange coneflower & Leaf & 2017 & Northern Italy & P. nigrum \\
\hline 39 & Echi_orig & Echinacea & Leaf & 2017 & Northern Italy & P. nigrum \\
\hline 40 & CBS 189.46 & Potato & Leaf & $-^{\mathrm{a}}$ & Cyprus & A. verrucaria \\
\hline 41 & CBS 372.50 & Coffea sp. & Twig & - & Colombia & $P$. roridum \\
\hline 42 & CBS 357.89 & Gardenia sp. & Unknown & - & Italy & P. roridum \\
\hline 43 & CBS 419.93 & Air & Air & - & Cuba & P. foliicola \\
\hline 44 & CBS 113121 & Decaying leaf & Leaf & - & Brazil & P. foliicola \\
\hline 45 & CBS 116537 & Soil & Soil & - & Spain & P. nigrum \\
\hline
\end{tabular}

a Dashes indicate undefined year of isolation. 
Sequence analyses. A sequence comparison was performed with sequences available in GenBank by means of the Basic Local Alignment Search Tool (BLAST) software package (https:// www.ncbi.nlm.nih.gov/). Phylogenetic analyses were conducted on the basis of maximum likelihood and Bayesian inference. The following reference strains were included for each species: CBS 189.46 (A. verrucaria), CBS 372.50 and CBS 357.89 (P. roridum), CBS 419.93 and CBS 113121 (P. foliicola), and CBS 116537 (P. nigrum). MEGA 7 software was used for the maximum likelihood analysis (Kumar et al. 2016). A 2,728-bp concatenated data set was obtained with the ITS, tub2, cmdA, tef1, and LSU sequences, whereas the phylogenetic analysis was performed separately for the ATP6 gene because of a lack of sequences for those reference strains. FindModel was used to select the best-fit nucleotide model of each region (https://www.hiv.lanl.gov/content/ sequence/findmodel/findmodel.html) as follows: Tamura-Nei (TrN) for LSU, TrN plus gamma for ITS and tub2, HasegawaKishino-Yano plus gamma for tefl, and general time reversible (GTR) plus gamma for $c m d A$, ATP6, and the concatenated tree. Maximum-likelihood trees were then constructed with bootstrap values based on 1,000 replications. The best-fit model of each data set was determined for the Bayesian analysis (Huelsenbeck and Ronquist 2001) using TOPALI version 2.5 (Milne et al. 2004); GTR plus gamma for ITS, tub2, cmdA, tef1, and ATP6; Felsenstein (1981) for LSU; and GTR plus invariable sites plus gamma for the concatenated tree. The Bayesian analysis was performed by discarding the first $25 \%$ of the saved trees as burn-in.

PCR-based detection. The portion of the $\mathrm{cmdA}$ gene showing the highest polymorphism between four characterized fungal species was identified by sequence analyses. This region was used to design forward and reverse primers for differentiation of four species. Thus, four sets of primers were designed: VERRCAL1×VERRCAL2 (A. verrucaria), FOLCAL1 $\times$ FOLCAL2 ( $P$. foliicola), NIGRCAL1 $\times$ NIGRCAL2 ( $P$. nigrum), and RORCAL1×RORCAL2 (P. roridum) amplifying 343, 354, 349, and $337 \mathrm{bp}$, respectively. Primer quality and specificity were checked by means of Primer3 (Whitehead Institute for Biomedical Research, Cambridge, MA) and BLAST sequence alignment (National Center for Biotechnology Information [NCBI]), respectively. The final volume of the PCR reaction $(25 \mu \mathrm{l})$ contained $10 \mathrm{ng}$ of DNA, $1 \times$ PCR buffer, $1.5 \mathrm{mM}$ of $\mathrm{MgCl}_{2}, 0.2 \mu \mathrm{M}$ of each primer, $0.2 \mathrm{mM}$ of dNTPs, and $1 \mathrm{U}$ of Taq DNA polymerase (Qiagen). The PCR cycling protocol consisted of $5 \mathrm{~min}$ at $94^{\circ} \mathrm{C}$ of initial denaturation; followed by 35 cycles of $30 \mathrm{~s}$ at $94^{\circ} \mathrm{C}, 30 \mathrm{~s}$ at $58^{\circ} \mathrm{C}$, and $1 \mathrm{~min}$ at $72^{\circ} \mathrm{C}$; and a final extension of $5 \mathrm{~min}$ at $72^{\circ} \mathrm{C}$. The PCR products $(5 \mu \mathrm{l})$ were analyzed by electrophoresis on a $1.2 \%$ agarose gel prestained with RedGel (Biotium, Hayward, CA), and the bands were visualized under ultraviolet light.

Pathogenicity tests. Six plant species were used for pathogenicity tests: lettuce (cultivar Gentilina; Maraldi Sementi, Cesena, Italy), lamb's lettuce (cultivar Palace; Meilland Richardier, Diemoz, France), cultivated rocket (cultivar Rucola Coltivata; La Semiorto, Sarno, Italy), wild rocket (cultivar Frastagliata Mazzocchi; Casalpusterlengo, Italy), spinach (cultivar Crocodile; Rijk Zwaan, The Netherlands), and basil (cultivar Genovese Gigante Italiko; Furia Sementi, Parma, Italy). Seeds were sown in 2-liter plastic pots in triplicate (nine seeds per pot) in a sterilized mixture of peat and perlite (80:20). The plants were grown in a greenhouse at 22 to $24^{\circ} \mathrm{C}$ before inoculation.

Following molecular identification, six strains that included all four fungal species were selected randomly for the pathogenicity tests (P. nigrum 13-1, P. nigrum Echi_orig, P. foliicola Bas4_1b, $P$. roridum AGR1r1, A. verrucaria AvITS6, and A. verrucaria Bas5_18). Isolates were grown on PDA amended with streptomycin sulfate for 10 days with a 12-h photoperiod in a growth chamber at 20 to $22^{\circ} \mathrm{C}$. Spore suspensions with a final spore concentration of $106 / \mathrm{ml}$ were prepared and used for the spray inoculation of aboveground organs of the plants ( $1 \mathrm{ml}$ of suspension/pot). The plants were artificially inoculated at 20 to 25 days after emergence, enclosed in a clear polyethylene moist chamber, covered by a transparent polyethylene film (to reach $100 \%$ relative humidity), and then moved to a growth chamber. They were maintained at temperatures of $24^{\circ} \mathrm{C}$ (day) and $22^{\circ} \mathrm{C}$ (night) at a photoperiod of $12 \mathrm{~h}$ and were watered twice a day. The moist chamber was removed 5 days postinoculation (dpi).

Disease severity was evaluated 7 to $10 \mathrm{dpi}$ using a diagrammatic scale for percentage of infected leaf area as follows (Gullino et al. 2017): 0 indicated symptomless plants, 1 indicated up to $5 \%, 2$ indicated 6 to $10 \%, 3$ indicated 11 to $25 \%, 4$ indicated 26 to $50 \%$, and 5 indicated 51 to $100 \%$. Symptoms were observed on 50 leaves per pot, searching for round, sunken, dark gray to brown spots. Disease severity was calculated as follows: Disease severity = $\Sigma$ (number of leaves $\left.\times \mathrm{X}_{0-5}\right) /$ (number of leaves), where $\mathrm{X}_{0-5}$ refers to an approximate class midpoint $\left(\mathrm{X}_{0}=0 \%, \mathrm{X}_{1}=3 \%, \mathrm{X}_{2}=8 \%, \mathrm{X}_{3}=\right.$ $18 \%, X_{4}=38 \%$, and $X_{5}=76 \%$ ).

\section{RESULTS}

Disease symptoms and fungal isolation. The observed symptoms of affected leafy vegetable and ornamental crops initially were circular, small 1- to 2-mm gray to brown spots with welldefined borders. Spots gradually expanded and coalesced to form necrotic lesions (around $30 \mathrm{~mm}$ ) with concentric rings, and the affected leaf tissue had a water-soaked consistency. The fungal isolates were obtained from symptomatic plant tissue by plating on PDA plates, and a single strain was isolated from each individual plant. Fungal isolates were subjected to morphological and molecular identification.

Morphological identification. Fungal isolates showed abundant white aerial mycelium and dark sporodochia distributed in concentric rings resembling the mycelium of the former Myrothecium genus. The shape of the conidia permitted the separation of the isolates in two groups belonging to two genera: Albifimbria (more subglobose conidia) and Paramyrothecium (more cylindrical conidia). Furthermore, the first group of isolates was identified morphologically as $A$. verrucaria showing nonseptate and subglobose to ellipsoidal conidia without appendages (average $7 \times$ $3 \mu \mathrm{m})$. They had white aerial mycelium with sporodochia, which had formed on the surface of the growth medium that contained dark to olive-green conidial masses.

Another group of isolates was Paramyrothecium-like and had almost identical morphological features. The isolates of this group were most similar to $P$. roridum, $P$. foliicola, and $P$. nigrum. These isolates showed nonseptate conidia with a cylindrical to ellipsoidal shape, hyaline to pale green color, and an approximate size of $6 \times$ $2 \mu \mathrm{m}$. Additional structures consisted of abundant and white aerial mycelium and sporodochia that had developed in the form of concentric rings that contained dark green to black conidial masses. These species were primarily isolated from necrotic plant tissues. $P$. foliicola was distinguished from other Paramyrothecium-like fungi by the production of orange exudates, which diffused in the PDA medium, and by shorter conidiophore stipes (approximately 0.6 times the length of those of $P$. nigrum and $P$. roridum).

Molecular identification and phylogenetic analyses. When the ITS sequences of the 36 new strains were compared with those available at NCBI nucleotide database, 19 gave the highest identity (100\%) with $A$. verrucaria, whereas 17 other strains showed 99 to $100 \%$ identity with different Paramyrothecium spp. Thirteen of the 17 strains were 99 to $100 \%$ similar to $P$. roridum, $P$. nigrum, $P$. viridisporum, $P$. acadiense, and a few others, whereas four strains (9-1, Bas4_1b, Bas4_m2, and AGR1r1) were 98 to 99\% similar to $P$. foliicola and $P$. roridum. Since the ITS region was not conclusive for many of the strains, the molecular characterization was continued with another five loci ( $t u b 2, c m d A$, tef1, LSU, and ATP6). Four loci (tub2, cmdA, tef1, and LSU) of 13 unidentified strains gave the highest identity with $P$. nigrum (reference strain 
CBS 116537): $100 \%$ for $t u b 2$ and LSU, $99 \%$ for $c m d A$, and $97 \%$ for tefl. Another four strains were similar $(99 \%)$ to both $P$. roridum and $P$. foliicola for LSU, but three of them were more similar to P. foliicola for tub2, cmdA, and tef1 (reference strains CBS 419.93 and CBS 113121), whereas one strain (AGR1r1) was more similar to $P$. roridum (reference strains CBS 372.50 and CBS 357.89). Furthermore, 17 unidentified strains were most similar to $P$. roridum (97 to $98 \%$ ) regarding the ATP6 gene, for which no P. nigrum and $P$. foliicola sequences were available at NCBI nucleotide database.

Phylogenetic analyses were then performed on gene portions of around 400 to $550 \mathrm{bp}$ for ITS, tub2, $\mathrm{cmdA}$, and tefl and portions of 600 to $800 \mathrm{bp}$ for ATP6 and LSU. The concatenated tree obtained on the basis of five partial sequences (ITS, tub2, cmdA, tef1, and LSU) was used to evaluate the genetic relatedness of all 39 studied fungal strains. Two different clusters were observed (Fig. 1); the first grouped all strains of $A$. verrucaria, including the reference CBS 189.46 strain, whereas the second was divided into two subclusters. One subcluster included the $P$. nigrum, $P$. viridisporum, $P$. foeniculicola, and P. cupuliforme strains with a $77 \%$ bootstrap value, and the other contained the $P$. roridum and $P$. foliicola strains with a $99 \%$ bootstrap value (together with their respective CBS reference strains). Furthermore, the P. nigrum subgroup (99\% bootstrap value) contained all of the studied $P$. nigrum strains, together with the reference CBS 116537 strain, which was clearly separated from the phylogenetically close Paramyrothecium spp. ( $P$. viridisporum, $P$. foeniculicola, and $P$. cupuliforme) (Lombard et al. 2016). The $P$. foliicola subgroup ( $66 \%$ bootstrap value) contained three of the studied strains (9-1, Bas4_1b, and Bas4_m2) together with the $P$.foliicola reference strains, which were separated from the $P$. roridum subgroup ( $73 \%$ bootstrap value) that contained the AGR1r1 strain and the CBS reference strain. The Bayesian consensus tree for five loci was concordant with the tree topologies obtained from the maximum likelihood analyses (data not shown). A single ATP6 phylogenetic tree was also able to differentiate four species, although the reference strain sequences of $P$. nigrum and $P$. foliicola were not available (Supplementary Fig. S1).

PCR-based detection. Variable regions that were able to discriminate $P$. foliicola, $P$. nigrum, $P$. roridum, and $A$. verrucaria were searched for in a multiple sequence alignment of the six loci. The highest diversity was identified in the $c m d A$ region of the studied strains, which was used to design the primers for differentiation of four identified species (Supplementary Fig. S2). Estimated amplicons using these primers were obtained for $P$. foliicola, $P$. nigrum, $P$. roridum, and $A$. verrucaria by conventional PCR. The amplicons were only observed in the species for which specific primers had been designed and not in those of the other three fungal species.

Pathogenicity assays. The first symptoms appeared as small necrotic spots on the leaf surface of four artificially inoculated plant hosts (lamb's lettuce, cultivated rocket, spinach, and basil), whereas necrosis was more distributed in patches and at the leaf margins on lettuce and wild rocket at $7 \mathrm{dpi}$ (Fig. 2). The necrotic lesions expanded and coalesced ( 3 to $4 \mathrm{~cm}$ of length) at $15 \mathrm{dpi}$, and this was followed by a general plant collapse. All studied strains were able to reproduce the leaf spot symptoms on their original hosts of isolation. Furthermore, the strains isolated from one host in natural conditions were able to infect other hosts under experimental conditions (Supplementary Table S3).

No important difference in disease severity was observed between the four fungal species on the cultivated and wild rocket at 1 week after inoculation, where disease severity ranged from 39 to $59 \%$, depending on the fungal species and strain (Fig. 3). On the other hand, P. foliicola (Bas4_1b) on lettuce, A. verrucaria (AvITS6) on lamb's lettuce, and $P$. nigrum (Echi_orig) on basil and spinach were the most severe $(39,42,26$, and $54 \%$ disease severity, respectively). Interestingly, pathogenicity of $P$. nigrum and $P$. foliicola (either naturally or following artificial inoculation) has not been reported previously.
The highest percentage of plant mortality (83\%) was observed in lamb's lettuce infected with A. verrucaria AvITS6 and spinach infected with $P$. nigrum Echi_orig, followed by wild rocket, cultivated rocket, and lettuce infected with $P$. foliicola Bas4_1b $(82,67$, and $50 \%$, respectively). In general, these strains appeared to be more detrimental to plant vitality on plant hosts that were different from the original plant hosts of isolation.

\section{DISCUSSION}

A phylogenetic inference study of the family Stachybotriaceae has revealed a polyphyletic origin of the Myrothecium genus, which has been revised and divided into 13 new genera (Lombard et al. 2016), including genera Paramyrothecium and Albifimbria. Of these genera, only $P$. roridum and $A$. verrucaria are presently considered prominent plant pathogens (Belisario et al. 1999; Bharath et al. 2006; Garibaldi et al. 2016b, c; Saira et al. 2017; Tulloch, 1972). Furthermore, there have been increasing reports of diseases caused by $P$. roridum; leaf spots have been reported in Italy, the United States, Brazil, China, Pakistan, and Ghana on crops such as lamb's lettuce, pepper, watermelon, and soybean, as well as on many ornamentals (Alam et al. 2017; Ben et al. 2015a, b, 2016, 2017; Farr and Rossman 2018; Fujinawa et al. 2016; Haudenshield et al. 2018; Jordan et al. 2018; Li et al. 2015). There have also been reports concerning $A$. verrucaria, and these have been prevalent on spinach and wild rocket in Italy (Garibaldi et al. 2016b, c) and on maize in Pakistan (Saira et al. 2017). On the other hand, to the best of the authors' knowledge, there have been no reports of $P$. nigrum and $P$. foliicola as plant pathogenic fungi. Only one CBS strain, isolated from soil, has been characterized on a morphological and molecular basis as P. nigrum (CBS 116537; Lombard et al. 2016), whereas a few gene sequences of other $P$. nigrum strains, originating from Catharanthus roseus, Vinca minor, and V. herbacea, are available at NCBI nucleotide database but without any phytopathological data or additional details. Furthermore, two $P$. foliicola strains from air and decaying leaf tissue (CBS 419.93 and CBS 113121), which were characterized in the study by Lombard et al. (2016), are the only available strains that have been described thus far.

A total of 36 new strains from six leafy vegetable species and two ornamental crops and three previously ITS-identified strains of $P$. roridum and $A$. verrucaria (Garibaldi et al. 2016a, b, c) were documented in this study as the causal agents of necrotic leaf spot and plant collapse. The morphological characteristics of the isolated fungi were similar, and they were considered members of the former genus Myrothecium. Microscopic observations of sporodochia and conidia allowed 19 A. verrucaria isolates to be identified, whereas the other 17 isolates could not be identified precisely as a result of the presence of morphologically identical species within the genus Paramyrothecium (Krisai-Greilhuber et al. 2017; Lombard et al. 2016). These Paramyrothecium-like isolates were most similar to $P$. roridum, P. nigrum, and P. foliicola (KrisaiGreilhuber et al. 2017).

The lack of distinct morphological characteristics suggested the use of a multilocus phylogenetic approach, since ITS-based identification alone was not conclusive to identify these species, as already reported previously (Chen et al. 2016). The ITS sequences confirmed the highest identity with $A$. verrucaria in those strains that were morphologically identified as that species. On the other hand, Paramyrothecium-like strains gave the highest identity to several Paramyrothecium spp., which could not be distinguished by means of ITS. Multilocus combined phylogenetic analysis, based on ITS, tub2, cmdA, tef1, and LSU, permitted the studied strains to be clearly identified as $A$. verrucaria and Paramyrothecium spp. (P. nigrum, $P$. foliicola, and $P$. roridum), which were further grouped into different subclusters and subgroups. All of the studied strains were grouped together with their corresponding reference strains. This study was in accordance with the multigene phylogenetic approach performed by Chen et al. 
(2016), which allowed the separation of $A$. verrucaria and $P$. roridum into different clades using five loci (SSU, LSU, ATP6, $E F 1-\alpha$, and $R P B 1$ ). Furthermore, our study confirmed the results of the combined phylogenetic analysis of Lombard et al. (2016) and allowed a precise separation of $P$. nigrum, $P$. roridum, and $P$. foliicola, together with the differentiation of $A$. verrucaria.
The molecular characterization of the 39 strains in this study revealed, for the first time, the natural presence of additional fungal species (besides A. verucarria and $P$. roridum) involved in the leaf spot disease reported in Northern Italy (Garibaldi et al. 2016a, b, c), and increased the number of reported hosts as well. Thus, apart from A. verucarria, $P$. foliicola has also been found to be involved in

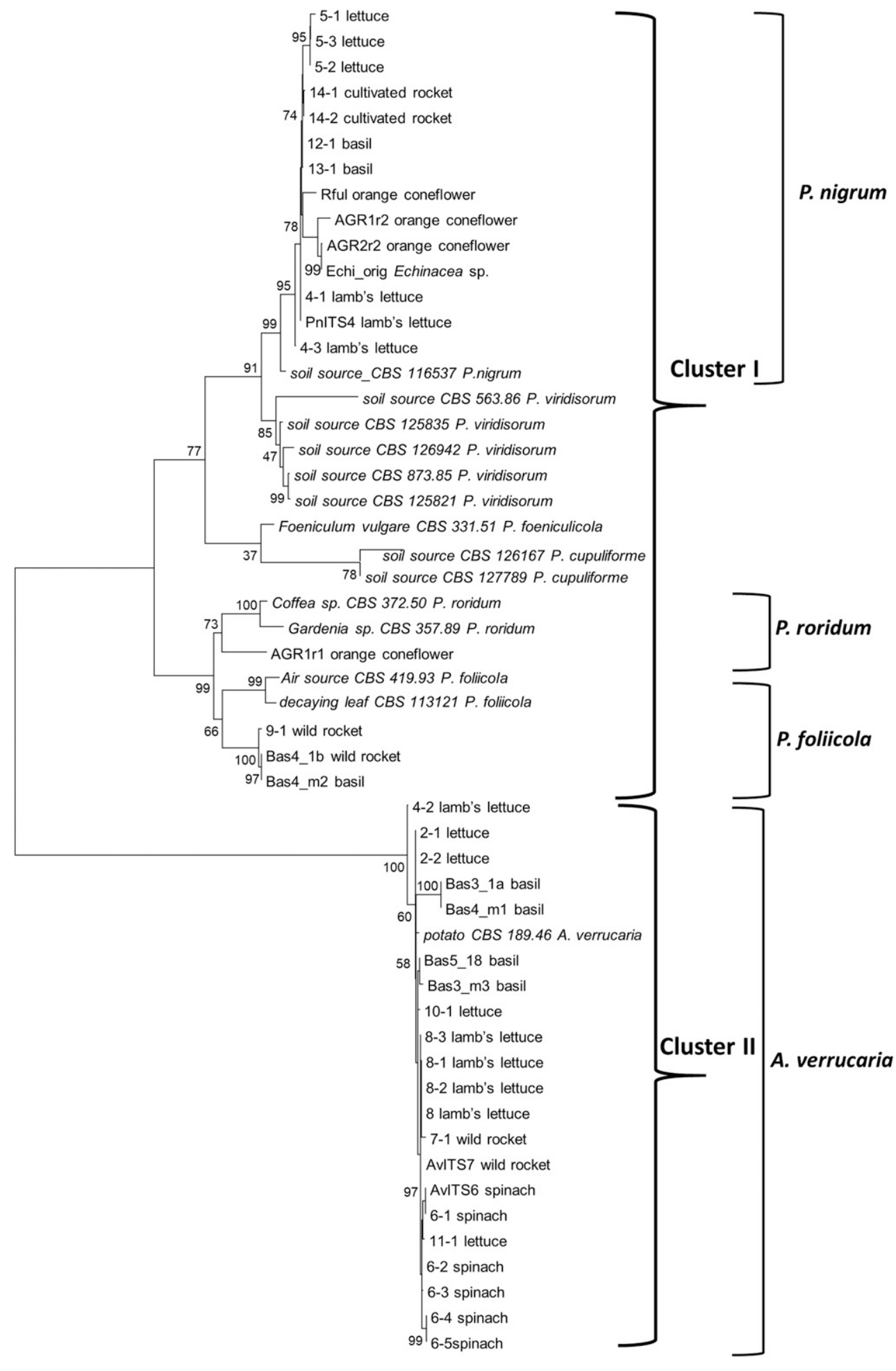

0.050

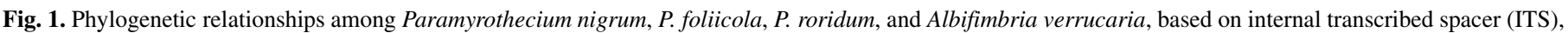

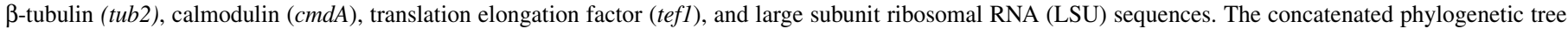

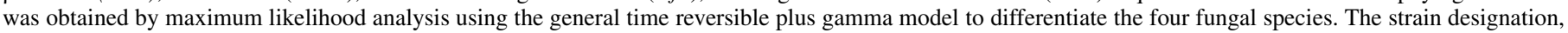

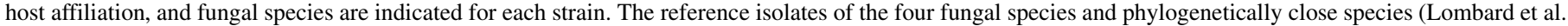
2016) are shown in italics. 
this disease on wild rocket (Garibaldi et al. 2016c). A. verrucaria has been identified from infected lamb's lettuce plants along with the previously reported, ITS-characterized P. roridum (Garibaldi et al. 2016a). Furthermore, the multilocus molecular identification in this study showed that what was thought to be $P$. roridum from lamb's lettuce is actually $P$. nigrum. The presence of either $A$. verrucaria or $P$. nigrum has been observed on infected lettuce. Three species (i.e., A. verrucaria, $P$. foliicola, and $P$. nigrum) have been identified in leaf spot-diseased basil. Furthermore, their presence has been observed on ornamentals: $P$. roridum and $P$. nigrum on orange coneflower and $P$. nigrum on Echinacea sp. When artificial inoculation was carried out, these four fungal species had a wider host range compared with that in natural conditions.

The sudden outbreak of the previously unknown leaf spot disease in Northern and Southern Italy, the involvement of four fungal species of the former genus Myrothecium, and the expansion of its

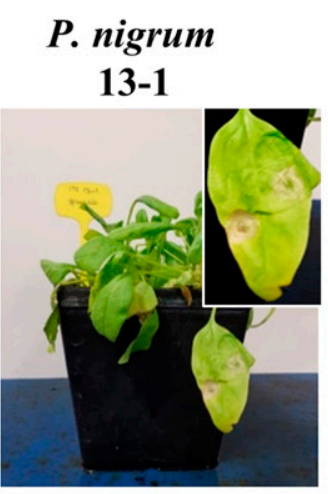

\section{P. foliicola Bas4_1b}
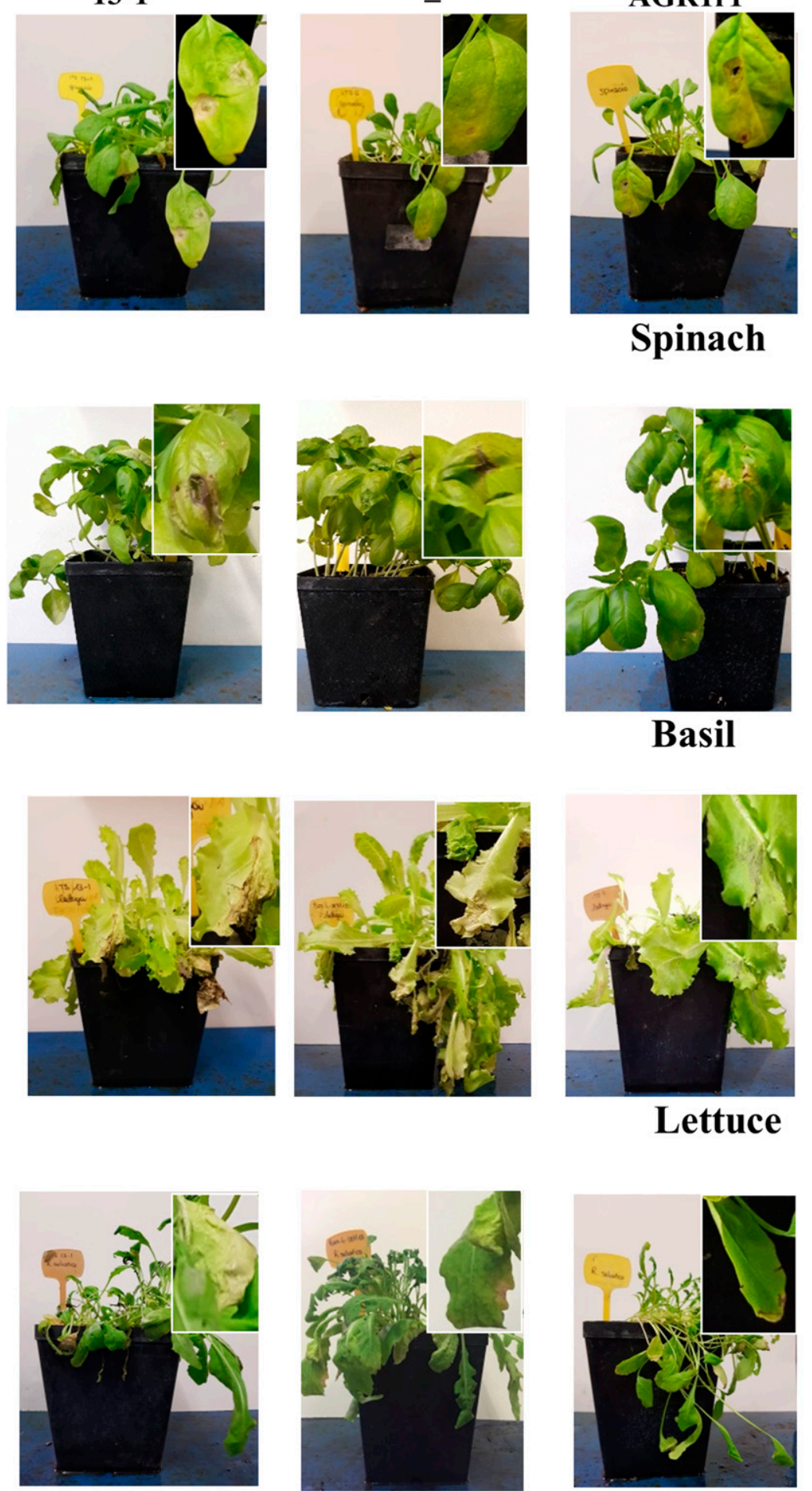

Basil

Lettuce

$P$. roridum AGR1r1

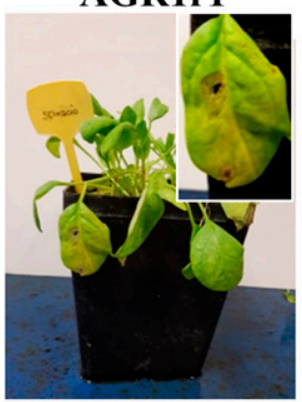

Spinach
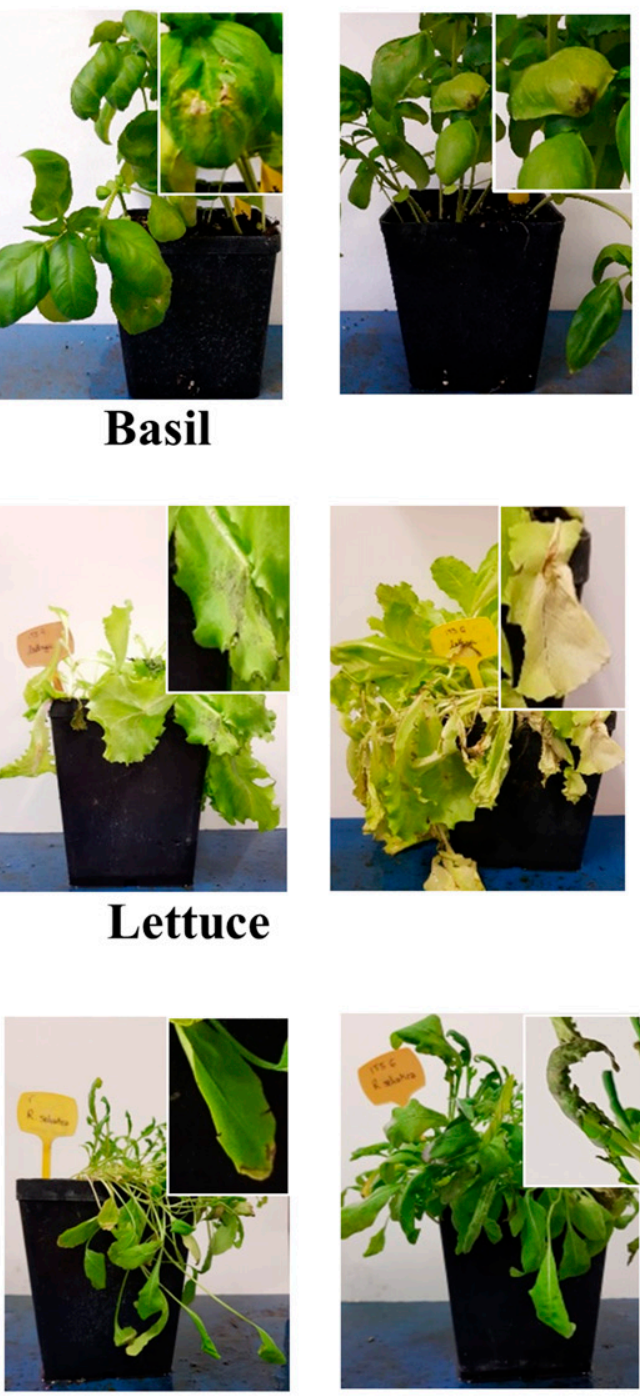

Wild rocket

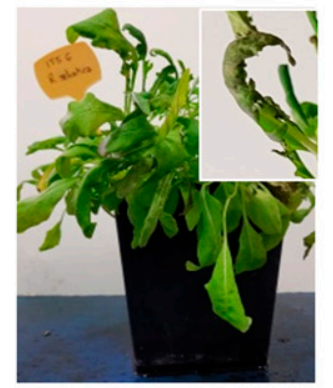

A. verrucaria AvITS6
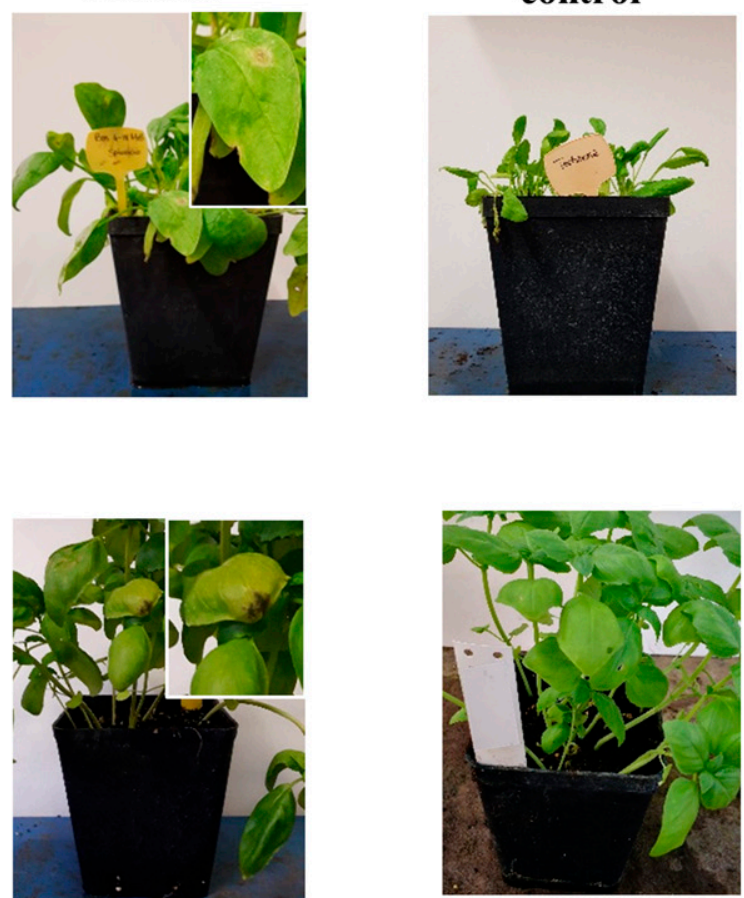

Non-inoculated control

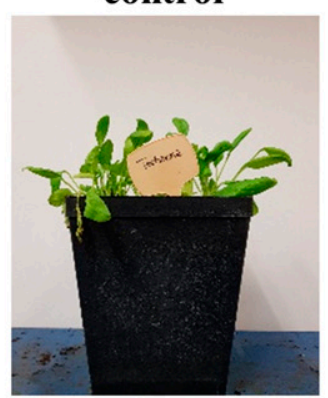

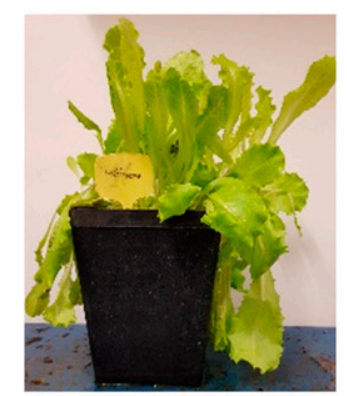

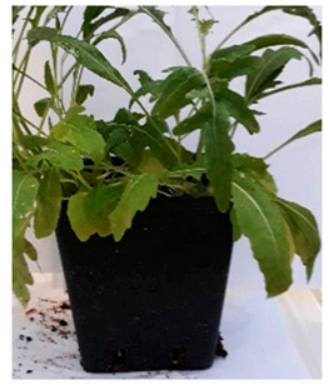

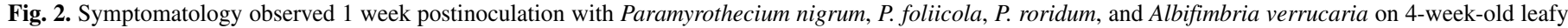
vegetable hosts. The strains used for pathogenicity tests are indicated at the top of the figure. 
natural host range could be related to climatic changes. Siciliano et al. (2017) reported a significant increase in leaf spot on spinach caused by $A$. verrucaria in increased temperature and $\mathrm{CO}_{2}$ conditions. Furthermore, the concentrations of the verrucarin $\mathrm{A}$ and roridin $\mathrm{E}$ mycotoxins were almost two times higher in increased temperature or $\mathrm{CO}_{2}$ conditions. Similar accounts of new necrotic leaf spot diseases have been reported on leafy vegetable crops in Northern Italy, such as those caused by Pleospora bjoerlingii and Fusarium equiseti (Garibaldi et al. 2007; Gullino et al. 2014).
Simulated increases in global air temperatures and $\mathrm{CO}_{2}$ levels have evidenced a higher leaf spot incidence on leaf beet by Pleospora bjoerlingii as a result of increasing $\mathrm{CO}_{2}$, whereas $F$. equiseti has been found to cause severe losses on lettuce as a result of temperature increases $\left(25\right.$ to $30^{\circ} \mathrm{C}$ ) as well as on wild rocket (30 to $35^{\circ} \mathrm{C}$ ) (Garibaldi et al. 2016d; Gilardi et al. 2017; Gullino et al. 2018). Furthermore, increased temperature and $\mathrm{CO}_{2}$ levels might be responsible for the emergence of the new pathogen races, as a result of the action of evolutionary forces on boosting pathogen

\section{Lamb's lettuce}
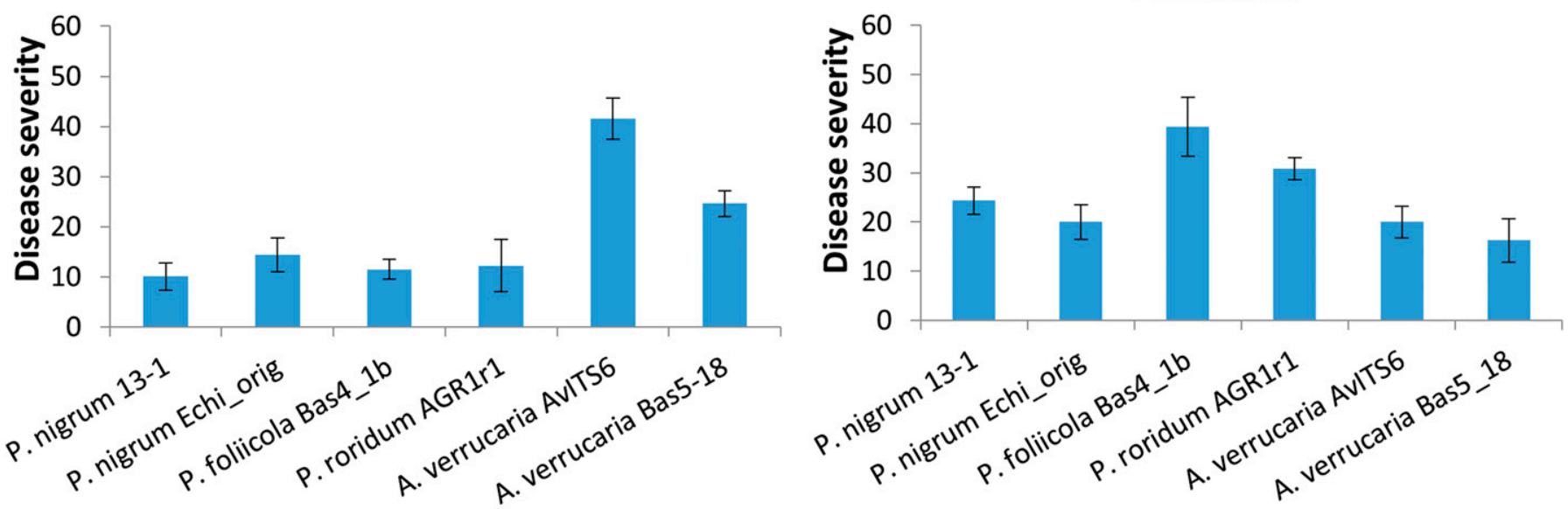

Cultivated rocket
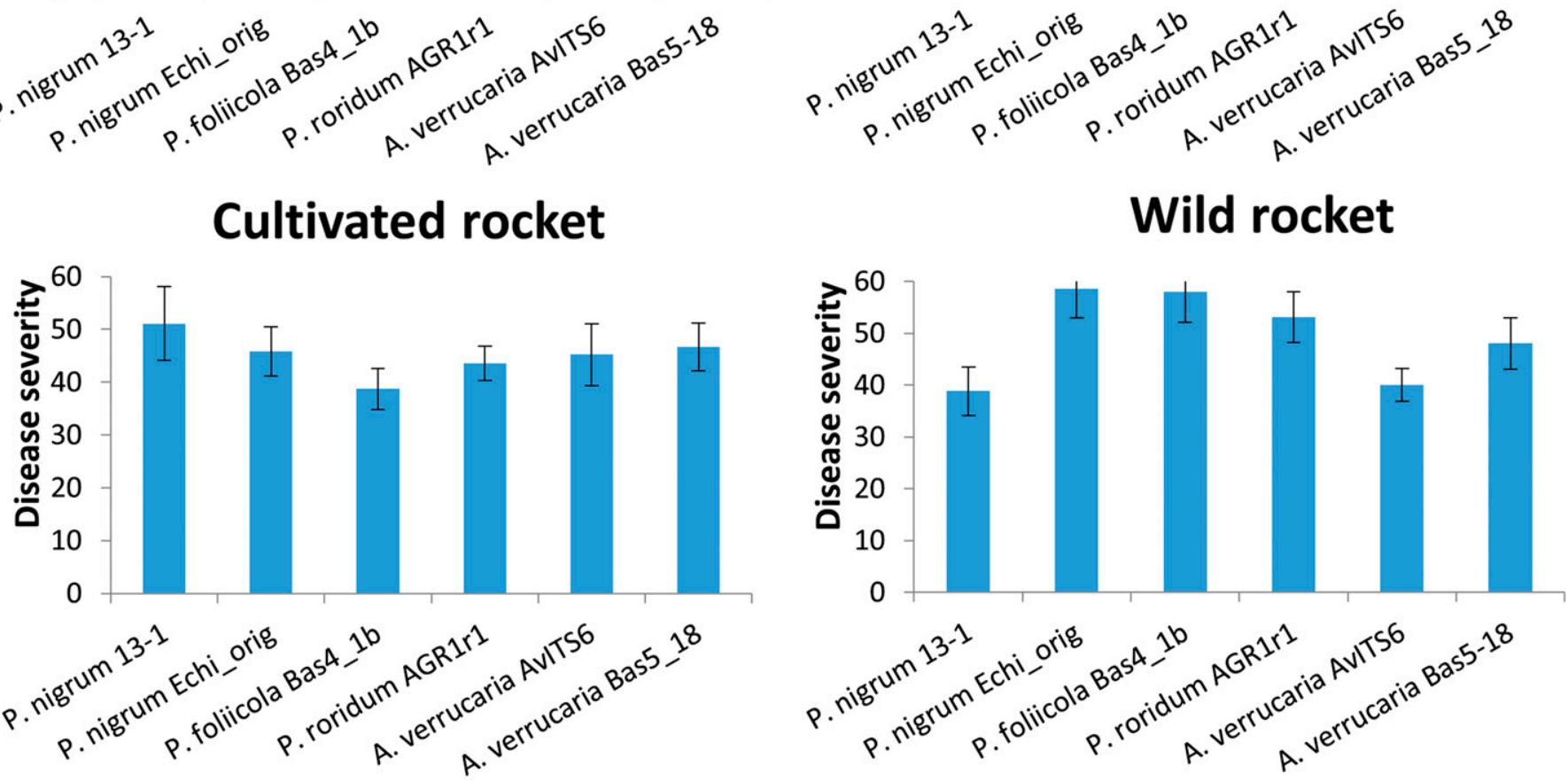

\section{Wild rocket}
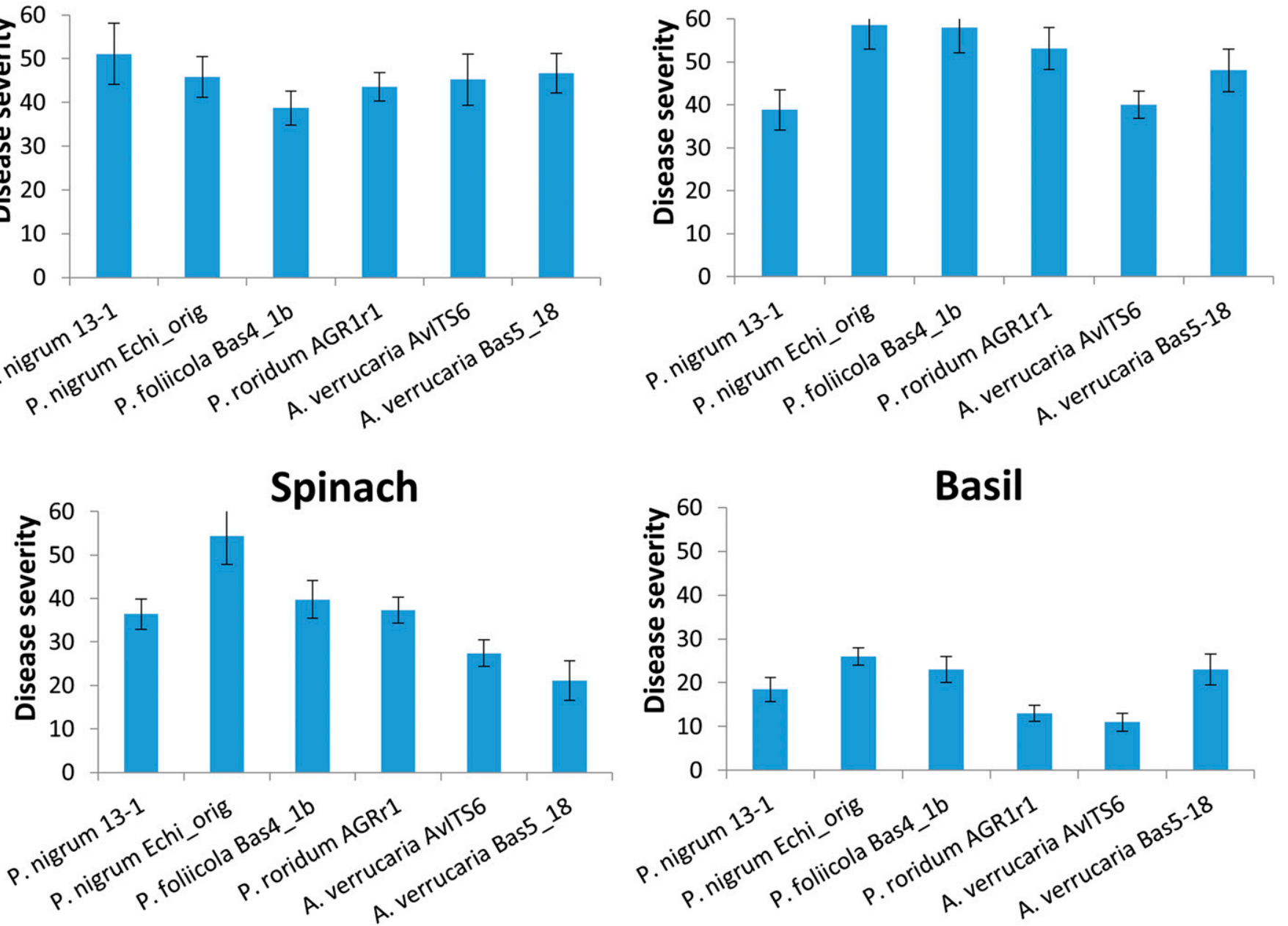

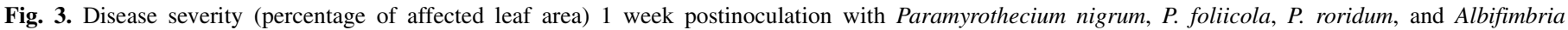
verrucaria on 4-week-old artificially inoculated leafy vegetable hosts. Values are means and standard deviations of nine replicates. 
populations through raised fecundity and the number of infection cycles (Chakraborty 2013).

Apart from a changing environment, the wide host range of the four studied fungal species should also be taken into consideration. We found an expanded host range of vegetable and ornamental crops affected by leaf spot disease, compared with 2015 when the disease was observed for the first time. It would be interesting to evaluate whether only host range expansion occurred or whether it was supported by a host shift, in which the fungus lost its capacity to infect the primary hosts such as tomato, gardenia, and others. Myrothecium-like fungi are common soil inhabitants and saprophytes on a range of plant residues but could possibly become phytopathogenic on various plant hosts as a result of their polyphagous nature. There have been examples of increased pathogen virulence on new hosts. Two new Diaporthe species (D. limonicola and D. melitensis), which represent saprobes, endophytes, or plant pathogens, were found to be associated with an emergence of a new destructive dieback disease of lemon plants in Europe, and they affected all tested Citrus species (Guarnaccia and Crous 2017). Ramularia collo-cygni, a European barley pathogen that has emerged in South Africa and Russia, has become pathogenic on oats and wheat (Havis et al. 2015; Huss et al. 2005; Kaczmarek et al. 2017). In China, a new species that affects stored asparagus has emerged (Fusarium asiaticum) (Zhu et al. 2013). Often the emergence of new diseases is associated with the introduction of pathogens into new geographic areas (Gladieux et al. 2015; Pautasso et al. 2015; Summerell 2017), but this appears unlikely for the four identified species in this study because they show moderately high intraspecies genetic variation, at least in the case of $A$. verrucaria and $P$. nigrum, for which a larger number of strains was available for diversity studies.

The risks posed by new disease outbreaks may also be associated with seed transmission of the causal agent, the globalization of the seed market, and changes in agricultural practices. Both $A$. verrucaria and $P$. roridum are seed-transmitted pathogens (Belisario et al. 1999; Nguyen et al. 1973).

$A$. verrucaria, $P$. roridum, $P$. foliicola, and $P$. nigrum have been found as single isolates obtained from individual plants. Furthermore, fungal isolates originated from different hosts, different locations, and different years of isolation, and all have shown the ability to cause leaf spot disease as single isolates. Further work involving field isolations and artificial inoculations is needed to establish whether mixed infections of these four species could be associated with the leaf spot disease in Italy 4 years after disease establishment.

In conclusion, this study is the first overview of the diversity of Myrothecium-like fungi involved in newly emerged leaf spot diseases of leafy vegetables and ornamental crops in Italy. The presence of four species (A. verrucaria, $P$. roridum, $P$. foliicola, and $P$. nigrum) as the causal agents of this disease was documented, and data about their symptomatology and pathogenicity were provided. Multilocus phylogenetic analyses allowed precise species differentiation and identified, for the first time, $P$. nigrum and $P$. foliicola as the causal agents of a plant disease. Studies using more loci and more reference strain sequences are needed to address interand intraspecific evolutionary questions pertaining to members of this important polyphyletic Stachybotriaceae family.

\section{ACKNOWLEDGMENTS}

We thank G. Tabone (Agroinnova, Turin, Italy) for help with carrying out the initial part of the pathogenicity assays.

\section{LITERATURE CITED}

Abbas, H. K., Tak, H., Boyette, C. D., and Shier, W. T. 2001. Macrocyclic tricothecenes are undetectable in kudzu (Puereria montana) plants treated with a high-producing isolate of Myrothecium verrucaria. Phytochemistry 58:269-276.
Alam, M. W., Rehman, A., Saira, M., Aslam, S., Hameed, A., Sarfraz, S., Muhammad, S., and Riaz, K. 2017. First report of leaf spot caused by Myrothecium roridum on watermelon in Pakistan. Plant Dis. 101:1053.

Anderson, K. I., and Hallett, S. G. 2004. Herbicidal spectrum and activity of Myrothecium verrucaria. Weed Sci. 52:623-627.

Belisario, A., Forti, E., and Corazza, L. 1999. First report of Myrothecium verrucaria from muskmelon seeds. Plant Dis. 83:589.

Ben, H.-Y., Gao, W., Qu, H.-Y., Chai, A.-L., Shi, Y.-X., Xie, X.-W., and Li, B.-J. 2016. New host record of Myrothecium roridum causing leaf spot on Abutilon megapotamicum from China. J. Phytopathol. 164:563-566.

Ben, H.-Y., Qu, H.-Y., Chen, L.-X., Zhang, J.-M., Ma, J., Zhang, X.-Y., Zhao, Y.-J., and Huang, D.-Y. 2017. First report of Myrothecium roridum causing leaf spot on Petunia hybrida in China. Plant Dis. 101:1956.

Ben, H.-Y., Qu, H.-Y., and Gao, W. 2015a. First report of Myrothecium roridum causing brown spot disease on Hiemalis begonia in China. Plant Dis. 99:1866.

Ben, H.-Y., Zhao, Y.-J., Chai, A.-L., Shi, Y.-X., Xie, X.-W., and Li, B.-J. 2015b. First report of Myrothecium roridum causing leaf spot on Anthurium andraeanum in China. J. Phytopathol. 163:144-147.

Bharath, B. G., Lokesh, S., Raghavendru, V. B., Prakah, H. S., and Shetty, B. G. 2006. First report of the occurrence of Myrothecium verrucaria in watermelon seeds from India. Australas. Plant Dis. Notes 1:3-4.

Bosio, P., Siciliano, I., Gilardi, G., Gullino, M. L., and Garibaldi, A. 2017. Verrucarin A and roridin E produced on rocket by Myrothecium roridum under different temperatures and $\mathrm{CO}_{2}$ levels. World Mycotoxin J. 10: 229-236.

Cappelli, C. 1996. Attacchi di Myrothecium roridum su coltivazioni di gardenia (Gardenia jasminoides) in Italia. Inf. Fitopatol. 46:47-49.

Carbone, I., and Kohn, L. M. 1999. A method for designing primer sets for speciation studies in filamentous ascomycetes. Mycologia 91:553-556.

Castlebury, L. A., Rossman, A. Y., Sung, G. H., Hyten, A. S., and Spatafora, J. W. 2004. Multigene phylogeny reveals new lineage for Stachybotrys chartarum, the indoor air fungus. Mycol. Res. 108:864-872.

Chakraborty, S. 2013. Migrate or evolve: Options for plant pathogens under climate change. Glob. Change Biol. 19:1985-2000.

Chen, Y., Ran, S. F., Dai, D. Q., Wang, Y., Hyde, K. D., Wu, Y. M., and Jiang, Y. L. 2016. Mycosphere essays 2. Myrothecium. Mycosphere 7:64-80.

Chen, Z. D., Li, P. L., Chai, A. L., Guo, W. T., Shi, Y. X., Xie, X. W., and Li, B. J. 2018. Crown canker caused by Paramyrothecium roridum on greenhouse muskmelon (Cucumis melo) in China. Can. J. Plant Pathol. 40:115-120.

Ciccarone, A. 1953. New records of tomato diseases in Italy. FAO Plant Prot. Bull. 3:11-12.

De Carolis, C. 1972. Myrothecium verrucaria (Alb. et Schw.) Ditm. ex Fr. su riso in Italia. Riso 21:253-258.

Domsch, K. H., Gams, W., and Anderson, T. 2007. Compendium of Soil Fungi, 2nd ed. IHW Verlag, Eching, Germany.

Farr, D. F., and Rossman, A. Y. 2018. Fungal Databases, U.S. National Fungus Collections, U.S. Department of Agriculture Agricultural Research Service. https://nt.ars-grin.gov/fungaldatabases/

Felsenstein, J. 1981. Evolutionary trees from DNA sequences: A maximum likelihood approach. J. Mol. Evol. 17:368-376.

Fish, W. W., Bruton, B. D., and Popham, T. W. 2012. Cucurbit host range of Myrothecium roridum isolated from watermelon. Am. J. Plant Sci. 3: 353-359.

Fujinawa, M. F., Pontes, N. C., do Vale, H. M. M., Santos, N. F., and Halfeld-Vieira, B. A. 2016. First report of Myrothecium roridum causing Myrothecium leaf spot on Begonia in Brazil. Plant Dis. 100:655.

Garibaldi, A., Gilardi, G., Berta, F., and Gullino, M. L. 2016d. Temperature and leaf wetness affect the severity of leaf spot on lettuce and wild rocket incited by Fusarium equiseti. Phytoparasitica 44:681-687.

Garibaldi, A., Gilardi, G., Bertetti, D., and Gullino, M. L. 2007. First report of leaf spot and root rot caused by Phoma betae on Beta vulgaris subsp. vulgaris (garden beet group) in Italy. Plant Dis. 91:1515.

Garibaldi, A., Gilardi, G., Franco-Ortega, S., and Gullino, M. L. 2016a. First report of leaf spot of lamb's lettuce (Valerianella olitoria) caused by Myrothecium roridum in Italy. Plant Dis. 100:1237.

Garibaldi, A., Gilardi, G., Franco-Ortega, S., and Gullino, M. L. 2016b. First report of leaf spot of spinach (Spinacia oleracea) caused by Myrothecium verrucaria in Italy. Plant Dis. 100:1786.

Garibaldi, A., Gilardi, G., Franco-Ortega, S., and Gullino, M. L. 2016c. First report of leaf spot of wild rocket (Diplotaxis tenuifolia) caused by Myrothecium verrucaria in Italy. J. Plant Pathol. 98:690.

Gilardi, G., Gisi, U., Garibaldi, A., and Gullino, M. L. 2017. Effect of elevated atmospheric $\mathrm{CO}_{2}$ and temperature on the chemical and biological control of powdery mildew of zucchini and the Phoma leaf spot of leaf beet. Eur. J. Plant Pathol. 148:229-236.

Gilardi, G., Gullino, M. L., and Garibaldi, A. 2018. Emerging foliar and soilborne pathogens of leafy vegetable crops: A possible threat to Europe. EPPO Bull. 48:116-127. 
Gladieux, P., Feurtey, A., Hood, M. E., Snirc, A., Clavel, J., Dutech, C., Roy, M., and Giraud, T. 2015. The population biology of fungal invasions. Mol. Ecol. 24:1969-1986.

Glass, N. L., and Donaldson, G. 1995. Development of primer sets designed for use with PCR to amplify conserved genes from filamentous ascomycetes. Appl. Environ. Microbiol. 61:1323-1330.

Groenewald, J. Z., Nakashima, C., Nishikawa, J., Shin, H. D., Park, J. H., Jama, A. N., Groenewald, M., Braun, U., and Crous, P. W. 2013. Species concepts in Cercospora: Spotting the weeds among the roses. Stud. Mycol. 75:115-170.

Guarnaccia, V., and Crous, P. W. 2017. Emerging citrus diseases in Europe caused by species of Diaporthe. IMA Fungus 8:317-334.

Gullino, M. L., Gilardi, G., and Garibaldi, A. 2014. Seed-borne pathogens of leafy vegetable crops. Pages 47-53 in: Global Perspectives on the Health of Seeds and Plant Propagation Material. Gullino, M. L., and Munkvold, G., eds. Springer, Dordrecht, The Netherlands.

Gullino, M. L., Gilardi, G., and Garibaldi, A. 2017. Evaluating severity of leaf spot of lettuce, caused by Allophoma tropica, under a climate change scenario. Phytopathol. Mediterr. 56:235-241.

Gullino, M. L., Pugliese, M., Gilardi, G., and Garibaldi, A. 2018. Effect of increased $\mathrm{CO}_{2}$ and temperature on plant diseases: A critical appraisal of results obtained in studies carried out under controlled environment facilities. J. Plant Pathol. 100:371-389.

Haudenshield, J. S., Pawlowski, M., Miranda, C., and Hartman, G. L. 2018. First report of Paramyrothecium roridum causing Myrothecium leaf spot on soybean in Ghana. Plant Dis. 102:2638.

Havis, N. D., Brown, J. K., Clemente, G., Frei, P., Jedryczka, M., Kaczmarek, J., Kaczmarek, M., Matusinsky, P., McGrann, G. R., Pereyra, S., Piotrowska, M., Sghyer, H., Tellier, A., and Hess, M. 2015. Ramularia collo-cygni-An emerging pathogen of barley crops. Phytopathology 105:895-904.

Huelsenbeck, J. P., and Ronquist, F. 2001. MRBAYES: Bayesian inference of phylogenetic trees. Bioinformatics 17:754-755.

Huss, H., Liebermann, B., and Miethbauer, S. 2005. Eine ernstzunehmende Krankheit auch bei Hafer und Weizen: Weitere Ausbreitung der Sprenkelkrankheit. Der Pflanzenarzt 58:8-10.

Jordan, B., Culbreath, A. K., Brock, J., and Dutta, B. 2018. First report of Myrothecium leaf spot caused by Myrothecium roridum on pepper in the United States. Plant Dis. 102:246.

Kaczmarek, M., Piotrowska, M. J., Fountaine, J. M., Gorniak, K., McGrann, G. R., Armstrong, A., Wright, K. M., Newton, A. C., and Havis, N. D. 2017. Infection strategy of Ramularia collo-cygni and development of Ramularia leaf spot on barley and alternative graminaceous hosts. Plant Pathol. 66:45-55.

Krisai-Greilhuber, I., Chen, Y., Jabeen, S., Madrid, H., Marincowitz, S., Razaq, A., Ševčíková, H., Voglmayr, H., Yazici, K., Aptroot, A., Aslan, A., Boekhout, T., Borovička, J., Crous, P. W., Ilyas, S., Jami, F., Jiang, Y. L., Khalid, A. N., Kolecka, A., Konvalinková, T., Norphanphoun, C., Shaheen, S., Wang, Y., Wingfield, M. J., Wu, S. P., Wu, Y. M., and Yu, J. Y. 2017. Fungal systematics and evolution: FUSE 3. Sydowia 69:229-264.

Kumar, S., Stecher, G., and Tamura, K. 2016. MEGA7: Molecular Evolutionary Genetics Analysis version 7.0 for bigger datasets. Mol. Biol. Evol. 33:1870-1874.

Lee, H. B., Kim, J. C., Hong, K. S., and Kim, C. J. 2008. Evaluation of a fungal strain, Myrothecium roridum F0252, as a bioherbicide agent. Plant Pathol. J. 24:453-460.

Li, B.-J., Chai, A.-L., and Ben, H.-Y. 2015. First report of Myrothecium roridum causing leaf spot of Swedish ivy in China. Plant Dis. 99:1447.

Liu, H. X., Liu, W. Z., Chen, Y. C., Sun, Z. H., Tan, Y. Z., Li, H. H., and Zhang, W. M. 2016. Cytotoxic trichothecene macrolides from the endophyte fungus Myrothecium roridum. J. Asian Nat. Prod. Res. 18:684-689.

Lombard, L., Houbraken, J., Decock, C., Samson, R. A., Meijer, M., Réblová, M., Groenewald, J. Z., and Crous, P. W. 2016. Generic hyper-diversity in Stachybotriaceae. Persoonia 36:156-246.
Milne, I., Wright, F., Rowe, G., Marshall, D. F., Husmeier, D., and McGuire, G. 2004. TOPALi: Software for automatic identification of recombinant sequences within DNA multiple alignments. Bioinformatics 20:1806-1807.

Nguyen, T. H., Mathur, S. B., and Neergaard, P. 1973. Seed-borne species of Myrothecium and their pathogenic potential. Trans. Br. Mycol. Soc. 61: 347-354, IN14-IN16.

O’Donnell, K., Kistler, H. C., Cigelnik, E., and Ploetz, R. C. 1998. Multiple evolutionary origins of the fungus causing Panama disease of banana: Concordant evidence from nuclear and mitochondrial gene genealogies. Proc. Natl. Acad. Sci. USA 95:2044-2049.

Pautasso, M., Petter, F., Rortais, A., and Roy, A.-S. 2015. Emerging risks to plant health: A European perspective. CAB Rev. 10:1-16.

Perry, R., Warrior, P., and Kerry, B., and Twomey, U. 2000. Effects of the biological nematicide, DiTera, on hatching of Globodera rostochiensis and G. pallida. Nematology 2:355-362.

Quezado Duval, A. M., Henz, G. P., Paz-Lima, M. L., Medeiros, A. R., Miranda, B. E., Pfenning, L. H., and Reis, A. 2010. New hosts of Myrothecium spp. in Brazil and a preliminary in vitro assay of fungicides. Braz. J. Microbiol. 41:246-252.

Rehner, S. A., and Samuels, G. J. 1995. Molecular systematics of the Hypocreales: A teleomorph gene phylogeny and the status of their anamorphs. Can. J. Bot. 73:816-823.

Ruma, K., Sunil, K., Kini, K. R., and Prakash, H. S. 2015. Genetic diversity and antimicrobial activity of endophytic Myrothecium spp. isolated from Calophyllum apetalum and Garcinia morella. Mol. Biol. Rep. 42: 1533-1543.

Saira, M., Rehman, A., Gleason, M. L., Alam, M. W., Muhammad, S., and Idrees, M. 2017. First report of Myrothecium verrucaria causing leaf spot of maize in Pakistan. Plant Dis. 101:633.

Siciliano, I., Bosio, P., Gilardi, G., Gullino, M. L., and Garibaldi, A. 2017. Verrucarin A and roridin E produced on spinach by Myrothecium verrucaria under different temperatures and $\mathrm{CO}_{2}$ levels. Mycotoxin Res. 33: 139-146.

Summerell, B. A. 2017. Managing biological invasions: The impact of exotic diseases on plant communities in Australia. Ann. Mo. Bot. Gard. 102: 324-330.

Trapp, S. C., Hohn, T. M., McCormick, S., and Jarvis, B. B. 1998. Characterization of the gene cluster for biosynthesis of macrocyclic trichothecenes in Myrothecium roridum. Mol. Gen. Genet. 257:421-432.

Tulloch, M. 1972. The genus Myrothecium Tode ex Fr. Mycol. Papers 130: $1-42$.

Vilgalys, R., and Hester, M. 1990. Rapid genetic identification and mapping of enzymatically amplified ribosomal DNA from several Cryptococcus species. J. Bacteriol. 172:4238-4246.

Weaver, M. A., Boyette, C. D., and Hoagland, R. E. 2016. Management of kudzu by the bioherbicide, Myrothecium verrucaria, herbicides and integrated control programmes. Biocontrol Sci. Technol. 26:136-140.

Weaver, M. A., Hoagland, R. E., Boyette, C. D., and Zablotowicz, R. M. 2009. Macrocyclic trichothecene production and sporulation by a biological control strain of Myrothecium verrucaria is regulated by cultural conditions. World Mycotoxin J. 2:35-43.

White, T. J., Bruns, T., Lee, S., and Taylor, J. 1990. Amplification and direct sequencing of fungal ribosomal RNA genes for phylogenetics. Pages 315-322 in: PCR Protocols. A Guide to Methods and Application. M. A. Innis, D. H. Gelfand, J. J. Sninsky, and T. J. White, eds. Academic Press, San Diego, CA.

Zhao, L., Liu, L., Hu, J.-C., Gao, J.-M., and Wand, S.-J. 2011. Isolation and identification of a marine fungus Myrothecium verrucaria Hmp-F73 producing trichothecene with insecticidal and antimicrobial activities. Chin. J. Biol. Control 3:331-337.

Zhu, P., Wu, L., Liu, L., Huang, L., Wang, Y., Tang, W., and Xu, L. 2013. Fusarium asiaticum: An emerging pathogen jeopardizing postharvest asparagus spears. J. Phytopathol. 161:696-703. 